\title{
Dry spell frequencies and their variability over southern Africa
}

\author{
Muhammad T. Usman ${ }^{1}$, C. J. C. Reason ${ }^{2, *}$ \\ ${ }^{1}$ Laboratory for Meteorology and Remote Sensing, Department of Geography, Federal University of Technology, \\ Bosso Campus, PMB 65, Minna, Nigeria \\ ${ }^{2}$ Department of Oceanography, University of Cape Town, Private Bag, Rondebosch 7701, South Africa
}

\begin{abstract}
Marked interannual fluctuations in rainfall are a fundamental aspect of southern African climate. This study uses dry spell frequency (DSF) to assess spatial and temporal patterns in the consistency of rainfall during the mid-summer (DJF) season and their relationships to interannual drought occurrences in southern Africa. The Climate Prediction Center Merged Analysis of Precipitation (CMAP) pentad data are used to identify dry spells, which are defined here as a pentad with mean daily rainfall less than $1 \mathrm{~mm}$. It was found that DSFs over most of southern Africa are highest (lowest) during El Niño (La Niña) events and that their occurrence is associated with shifts in the location of the tropical-temperate-trough (TTT) systems that are the dominant rain-producing systems over much of southern Africa. The latter are tropical-extratropical cloudbands that link a tropical low over low latitude southern Africa with a westerly disturbance passing south of the landmass. A preferred zone of occurrence of high DSFs, within which the interannual range is also highest, lies across the 20 to $25^{\circ} \mathrm{S}$ band in southern Africa and is identified as the drought corridor. This region often experiences half or more of the season under dry spells. In addition, a tendency during 1979 to 2002 towards an increasing frequency of heavier rainfall events was observed over Angola/Namibia in the west and Tanzania/Mozambique in the east. Only a small area in central southern Africa showed the reverse tendency.
\end{abstract}

KEY WORDS: Dry spell frequency $\cdot$ Southern Africa $\cdot$ ENSO

Resale or republication not permitted without written consent of the publisher

\section{INTRODUCTION}

Southern Africa is a region of significant rainfall variability on a range of temporal and spatial scales (e.g. Tyson 1986, Nicholson \& Entekhabi 1987, Lindesay 1998) and is prone to serious drought and flood events. Limitations in water availability during these events frequently have a significant impact on rain-fed agriculture and the cultivation of staple grain crops (Schulze 1997). Several studies have examined rainfall variability over southern Africa (e.g. Harrison 1984a,b, Taljaard 1986, Nicholson \& Entekhabi 1987, Lindesay 1988, Walker \& Shillington 1990, Lindesay \& Jury 1991, Lyons 1991, Jury 1992, 1999, Mason 1995, Levey \& Jury 1996, Todd \& Washington 1998, Cook 2000, Reason \& Rouault 2002). Many of these studies have identified a dipole pattern in rainfall across subtropical southern Africa during austral summer. This pattern has also been associated with the dynamics of moisture convergence in the region and may be related to shifts in the location of the South Indian Convergence Zone (SICZ) (Cook 2000, Todd \& Washington 1999, Todd et al. 2004).

Like many previous studies, the variability in rainfall was examined using monthly or seasonal anomalies. Recently, Washington \& Todd (1999) and Tennant \& Hewitson (2002) examined intra-seasonal variability using daily rainfall data. These authors showed evidence of the dominant patterns of intraseasonal rainfall variability and helped to confirm previous suggestions by Harangozo \& Harrison (1983) and Tyson (1986) concerning the role that tropical temperate 
troughs (TTTs) play in determining the nature of the summer season over southern Africa. TTTs are tropical-extratropical cloudbands that link a tropical low over low-latitude southern Africa with a westerly disturbance passing south of the landmass. Typically, the bands line up NW-SE across subtropical southern Africa, with a significant polewards export of moisture and heat, and good rainfall in the vicinity of this synoptic system. In some seasons, the TTTs tend to be located further east when the tropical source is over the eastern margins of the sub-continent or even Madagascar. If this is the case, then most of southern Africa tends to experience significantly reduced rainfall.

The earlier studies of Washington \& Todd (1999) and Tennant \& Hewitson (2002) were limited in temporal coverage and to South Africa, respectively. Thus, there is room for additional studies over the entire subcontinent south of the equator that use now available merged (rain gauge and satellite-derived) rainfall data.

Applications of rainfall variability studies to many fields such as agriculture and water resource management need more detailed information than just departures from a 'mean' state. For example, it is known that a season with above-average rainfall over an agricultural region may not be any better than a belowaverage season if the rains are not well distributed in either time or space. For crop cultivation, the consistency with which minimally required rainfall is received is more important than the total received over time. Crops are more likely to do well with uniformly spread 'light' rains than with a few 'heavy' rains interrupted by dry periods. The timing of breaks in rainfall (dry spells) relative to the cropping calendar rather than total seasonal rainfall is fundamental to crop viability. With this in mind, the objective in this study is to examine the interannual variability of the occurrence and severity of dry spells in austral summer rainfall over southern Africa using pentads (5 d amounts) as the basic unit of the rainfall analyses presented below. In particular, the analyses are applied towards identifying regions of southern Africa that are more susceptible to drought and to pronounced variability in the temporal distributions of their summer rainfall.

\section{DATA AND METHODOLOGY}

Climate Prediction Center (CPC) Merged Analysis of Precipitation (CMAP) mean pentad rainfall data (Xie \& Arkin 1997) updated to July 2002 are used herein. The CMAP data analysed here come from the version based on a merge of rain guage measurements with satellite estimates (infra-red, Special Sensor Micro-wave Imager, Advanced Microwave Sounding Unit data) only; i.e. the version that also incorporates model data input is not used. The $2.5^{\circ} \times 2.5^{\circ}$ grid resolution of the CMAP data may not adequately capture local topographic and vegetation effects. However, since the study essentially considers large-scale patterns over southern Africa, it is believed that the data are adequate.

Since the variability of cumulative rainfall does not fully explain impacts on agriculture and a few heavy rainfall events may lead to an erroneous impression that a growing season is good, it is preferable to consider other measures such as the dry spell frequency (DSF) during the season. For example, Sivakumar (1992) showed that the DSF ranging between 2 and 3 pentads in West Africa was independent of long-term seasonal means with a direct consequence for agriculture. Dry spells relate directly to agricultural impacts since their frequency and duration indicate the degree of stress plants are exposed to. In addition, an analysis of dry spells can indicate spatial differences in the consistency of rainfall, thereby providing an assessment of the occurrence of rain-producing systems. Similar to Usman (1994), this study defines a dry spell as a pentad (5 d) with less than $5 \mathrm{~mm}$ of rainfall. It should be noted that the Famine and Early Warning System (FEWS) of the United States Agency for International Development uses $0.85 \mathrm{~mm}$ of rain as the minimum value for a wet day (pentad equivalent $4.25 \mathrm{~mm}$ ).

The pentad timeframe is appropriate to cover the TTT rain-producing systems that are responsible for most of the regional rainfall. Washington \& Todd (1999) showed that these systems occur infrequently, typically lasting between 3 and $4 \mathrm{~d}$, and that consecutive events are separated by about $5 \mathrm{~d}$. The December to February season is selected for analysis because of its relevance as the peak of the growing season within the major cropping areas and because this is typically when El Niño Southern Oscillation (ENSO) impacts over southern Africa reach their maximum strength (Nicholson \& Selato 2000, Reason et al. 2000). For example, the seasonal maize crop flowers within December to February, after germinating in late October or November, and needs on average 120 growing days from planting to harvesting. Thus, December marks the beginning of the critical 4 mo (December to March) period outside which the chances of a good harvest are considerably reduced. The health of the crops and the possible yield are therefore closely tied to the effectiveness of rainfall during this time. In addition, Tennant \& Hewitson (2002) provided evidence that the dominant weather systems (TTTs) and rainfall characteristics during December to February were uniquely different from those of other months within the summer rainy season from November to March. Although their results are for South Africa alone, they are likely to be true for most of southern Africa since the tropical source of these 
weather systems lies well north of South Africa.

A time series of dry spell occurrences is generated and then subjected to further analysis to identify spatio-temporal patterns. Deviations from the 1979 to 2002 mean are used to identify extreme seasons and to diagnose ENSO impacts on the intra-seasonal rainfall variability as compared to total seasonal rainfall. The maximum (minimum) number of dry spell occurrences in a season during the 1979 to 2002 period is also extracted for each grid point to get an idea of the worst (best) season. The difference between these quantities is taken to indicate the range of variability and, by inference, the degree of consistency in the rainfall regime. The number of dry-spell-free seasons during 1979 to 2002 is tallied as an indication of the spatio-temporal variability of the dominant rainfall systems. The pattern is then discussed in association with the alignment of the TTTs. To identify the spatial character of dry spells

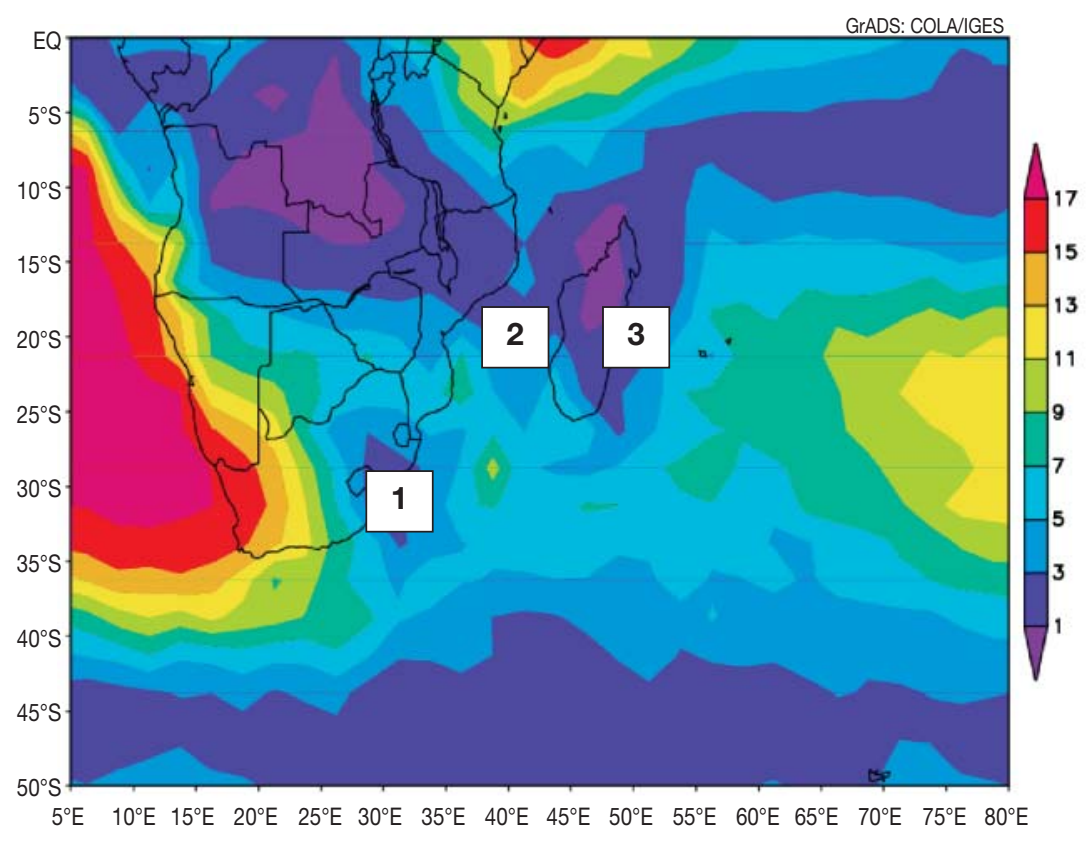

Fig. 1. Mean frequency of dry spells over southern Africa averaged over $1979 / 80$ to 2001/02 austral summer seasons. Summer is defined as December to February here and throughout the study. The colour key ranges from 1 to 17 shaded at an interval of 2 . The 3 nodes of preferred locations of tropical temperate troughs (TTTs) are labelled as 1, 2, 3 during the study period, the number of times each grid point was cumulatively dry one-third, and more than half, of the season, is counted. This is presented as an intensity-frequency map and then discussed in relation to the existence of a drought corridor over the region.

A linear regression is superimposed on the respective time series of dry spell occurrences and total rainfall at each grid point to investigate any coherent increase or decrease through the record. Statistical significance is assessed by correlating the series with time and testing the coefficient at the 0.05 probability level. Areas where significant rates of change in both DSF and total seasonal rainfall during 1979/80 to 2001/02 are then classified such that areas with increasing DSF and reducing rainfall are flagged as 1 on their respective grids and the reverse in both cases as 0 . The 2 fields are then overlaid additively and subtractively to identify areas that are either getting drier or wetter or areas that are witnessing increasing frequency of heavier or lighter rainfall events, respectively.

\section{RESULTS}

\subsection{Climatology}

The average DSF during austral summer (December to February inclusive) computed for the 1979/80 to
2001/02 period is shown in Fig. 1. As expected, dry spells occur most often over the desert and semi-desert areas of the southwest (Namibia, Botswana and western South Africa) and least often near the Inter-Tropical Convergence Zone (ITCZ) that stretches across northern Madagascar, northern Mozambique and Zambia and then northwards through the Congo basin during the summer. Rainfall is received most consistently over the southern Congo and northeastern Angola, in the confluence region between tropical air coming from the western Indian and southeast Atlantic Oceans. The influence of the ITCZ across northern Madagascar, the westerly storm tracks along $45^{\circ} \mathrm{S}$ and the orographic effects in Lesotho/eastern South Africa and eastern Madagascar are also seen. The lack of a clear NW-SE linkage between the tropical lows and the mid-latitude troughs indicates the transient nature of the TTTs. These weather systems, although bringing most of the summer rainfall, occur relatively infrequently (Washington \& Todd 1999) and are therefore not visible when consistency is used as a criterion for examining the patterns, as is the case here.

However, there are 3 nodes of low DSF over subtropical southern Africa which correspond to preferred locations for the TTTs and their associated cloud bands and rainfall. These nodes are the Drakensberg mountain region of Lesotho/eastern South Africa, within the Mozambique Channel and, lastly, off eastern and southeastern Madagascar. These nodes are hereafter 

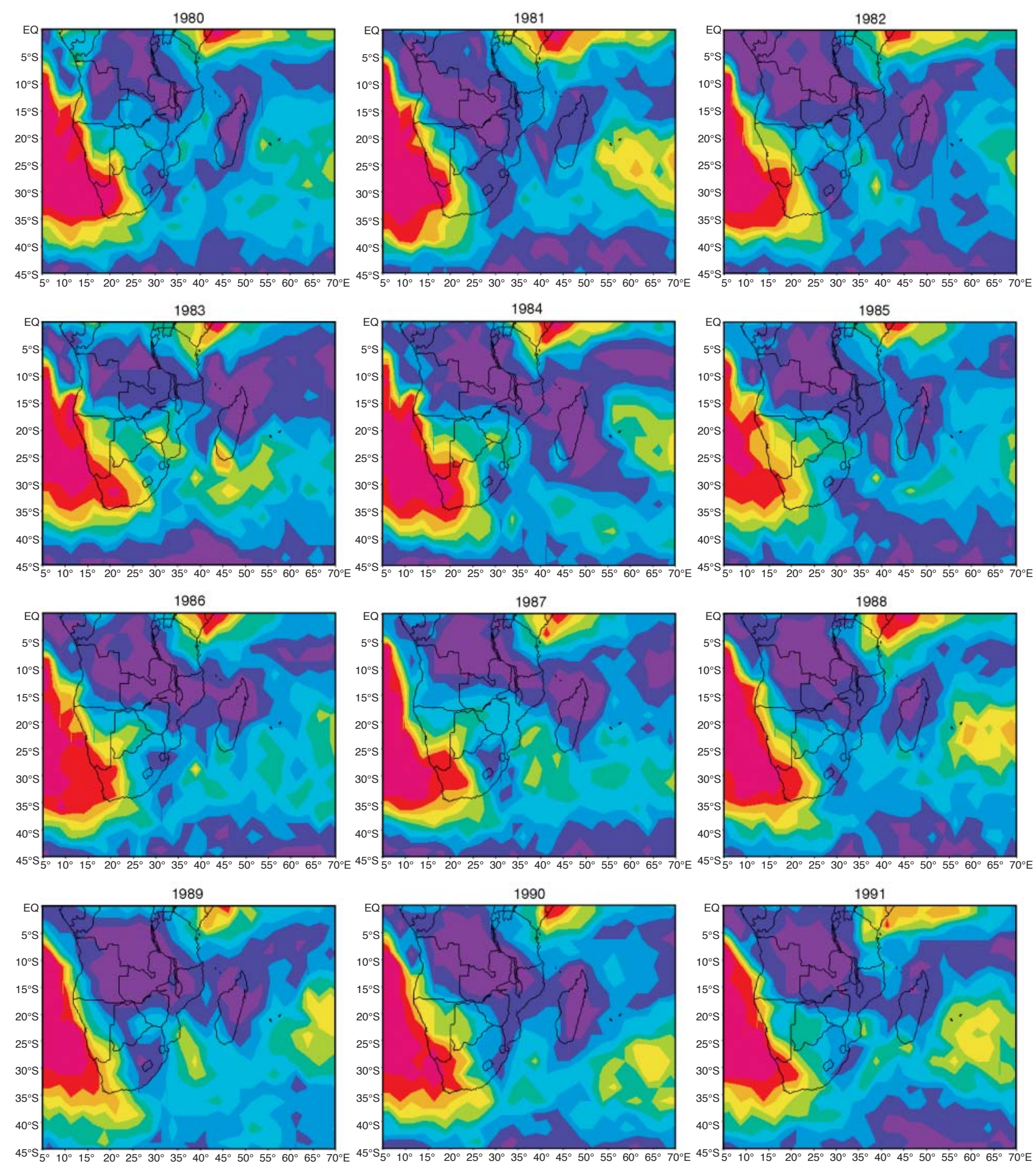

Fig. 2. Frequency of dry pentads for each summer from 1979/80 to 2001/02, showing patterns of consistency in rainfall. Seasons are labeled using the year to which January belongs. Extreme seasons are clearly marked by differences in the alignment of the dominant rainfall systems. El Niño summers are considered to be 1982/83, 1986/87, 1991/92, 1997/98 and La Niña summers 1988/89, 1995/96, 1998/99, 1999/00

referred to as Nodes 1, 2 and 3, respectively (Fig. 1). Similar to Lindesay (1988) and Washington \& Todd (1999), consistent Node 1 (Lesotho/eastern South Africa) links are associated with good rainfall seasons across southern Africa while Node 3 (Madagascar) links are associated with poor rainfall seasons across most of southern Africa. Node 2 (Mozambique Channel) links bear resemblance to the leading empirical 

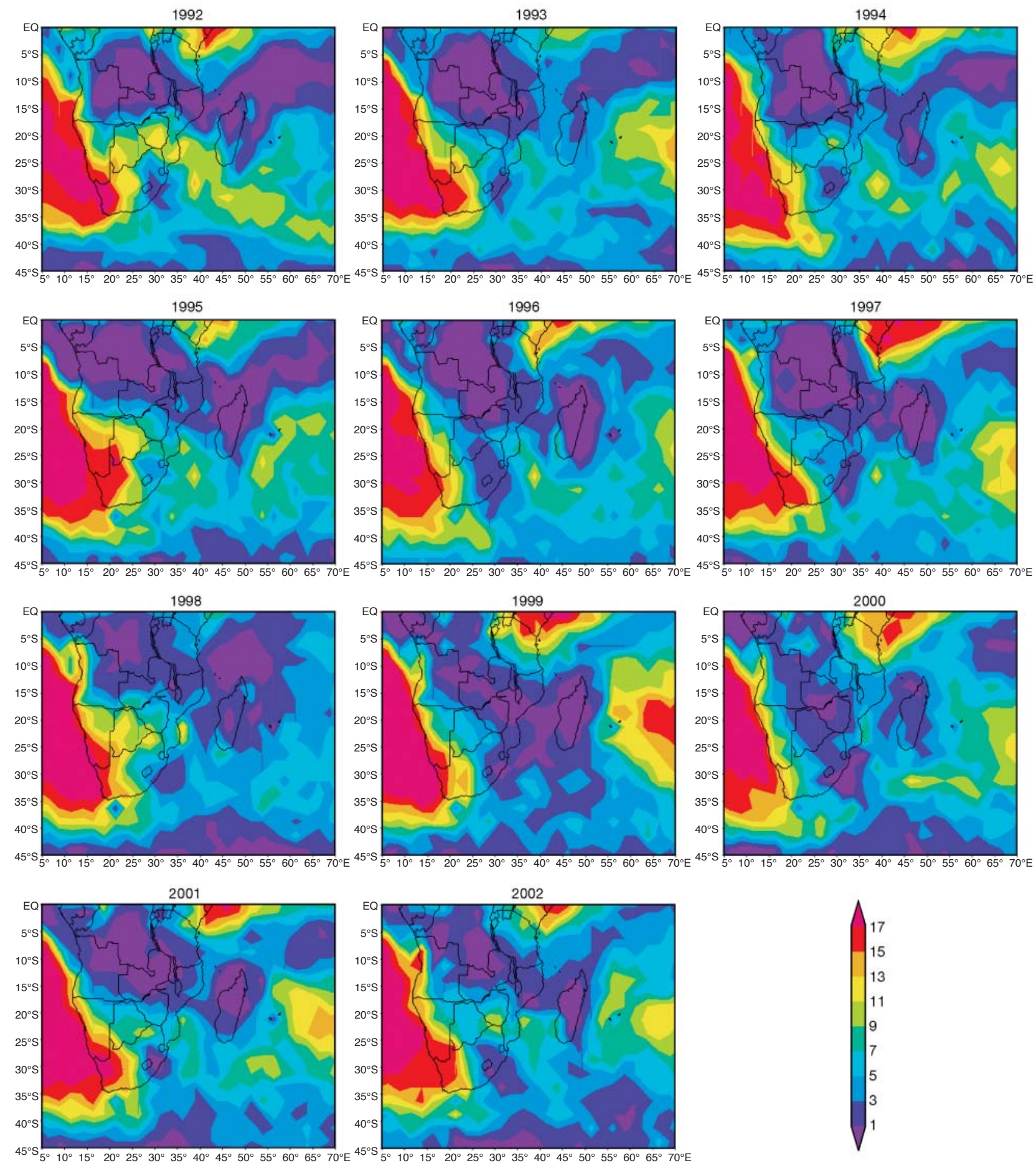

Fig. 2 (continued)

orthogonal function (EOF) pattern for the month of December derived by Washington \& Todd (1999) and are identified as distinct from Node 3 links. These are observed to be associated with consistent (inconsistent) rains over the eastern (western) half of southern Africa south of $20^{\circ} \mathrm{S}$.

\subsection{Interannual variability in DSF}

Fig. 2 shows the variability in DSF over southern Africa for each of the 23 summers during 1979 to 2002. The very wet seasons of 1980/81 and 1999/00 were characterised by a NW-SE axis of low DSF whereas the 

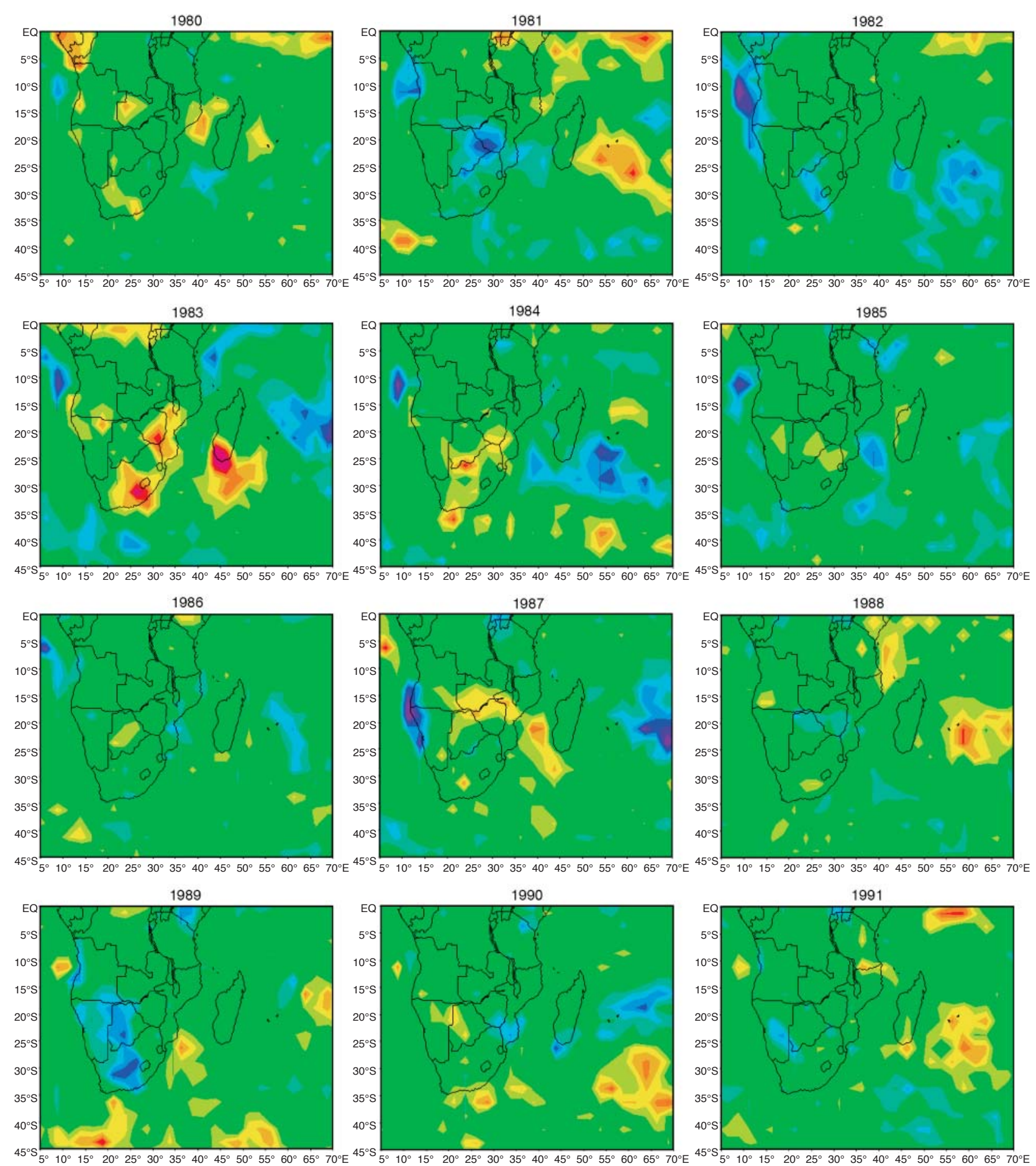

Fig. 3. Seasonal deviations from mean dry spell frequency plotted in Fig. 1 showing patterns during each ENSO and non-ENSO season from 1979/80 to 2001/02. Seasons are labeled using the year to which January belongs. El Niño summers are considered to be 1982/83, 1986/87, 1991/92, 1997/98 and La Niña summers 1988/89, 1995/96, 1998/99, 1999/00

dry 1982/83, 1986/87, 1991/92, 1994/95, 1997/98 and 2001/02 seasons are all marked by higher DSFs across southern Africa near 20 to $25^{\circ} \mathrm{S}$ and an eastward extension of the South Atlantic region of high DSFs into South Africa and Namibia. This is in line with the ob- servation by Todd \& Washington (1999) of eastward (westward) shifts in the Indian Ocean and South Atlantic subtropical highs during dry (wet) seasons. In addition, the 1982/83, 1991/92 and 2001/02 seasons share a common feature in the existence of a secondary 

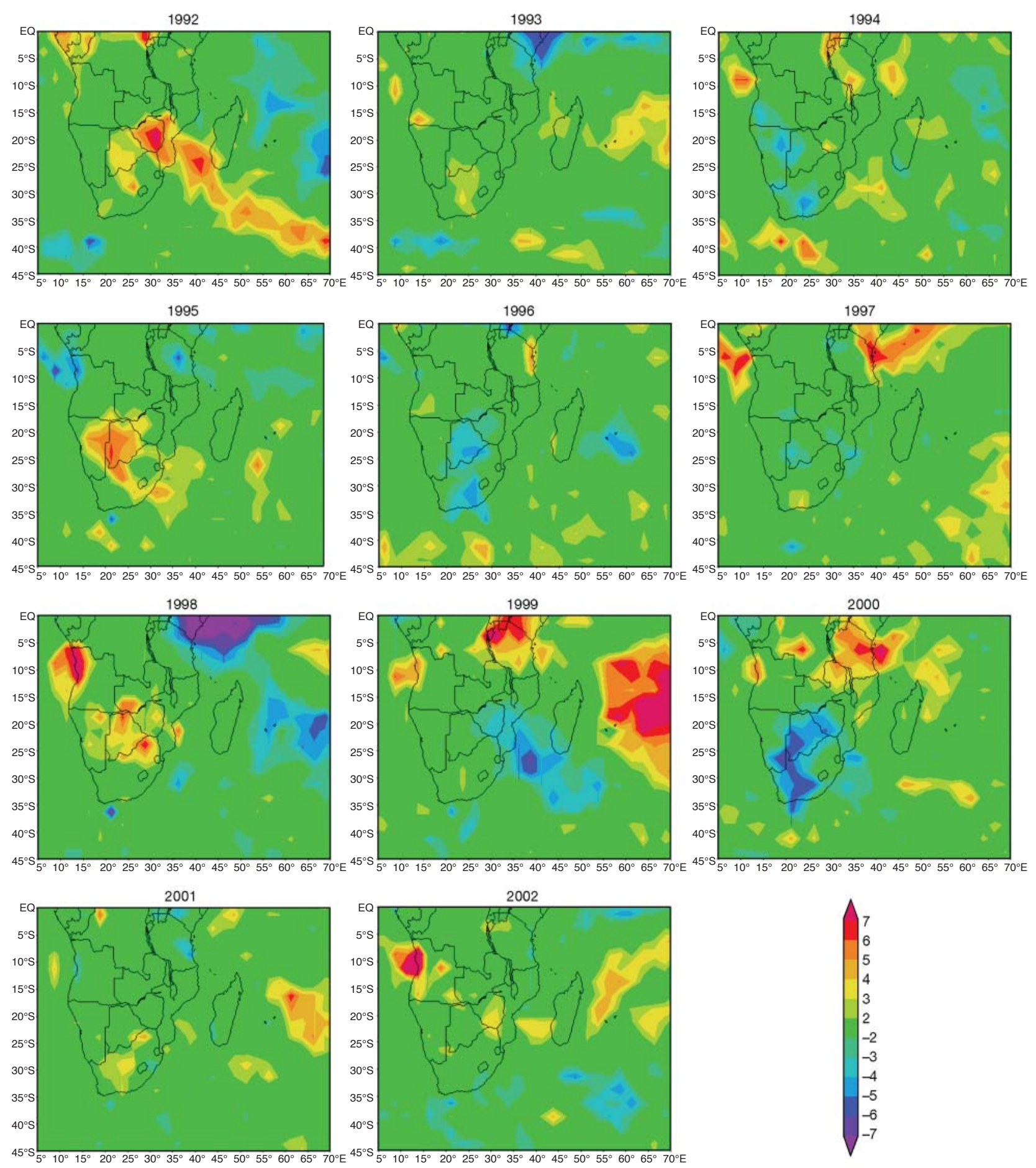

Fig. 3 (continued)

maximum DSF over southern Zimbabwe. Relatively weaker maxima are also observed over the same area during the 1983/84 and 1993/94 seasons. Although the northern half of Madagascar is virtually free of dry spell incidences since the ITCZ lies across it in summer, the southern half often experiences significant dry spells.
The highest frequencies over the westerly trough axis south of Africa occurred during 1988/89, 1995/96 and 1996/97, suggesting that TTTs were relatively less important rain-producing systems during these seasons since the necessary mid-latitude input (cold front or mid-latitude depression) was less evident. It 
is noted that the 2 identified alignments of TTTs associated with rainfall variability over southern Africa (e.g. Washington \& Todd 1999, Cook 2000) are not clearly discernible in most seasons if a frequency threshold of 3 dry spells in a season is used. This is an indication of their transient nature as further analysis shows.

Fig. 3 shows the influence of El Niño (La Niña) in tending to increase (decrease) the DSF relative to the summer mean over much of southern Africa, with the reverse tendency in equatorial East Africa. The impact on DSF of the 1982/83, 1991/92, 1997/98 El Niños and the 1988/89,1995/96, 1998/9 and 1999/00 La Niñas are evident (note that the same years as in Reason et al. [2000] and Allan et al. [2003] are chosen - these are based on significant departures in the Southern Oscillation Index (SOI) and in central and eastern equatorial Pacific sea surface temperature, SST). The dry and wet seasons identified earlier are also clearly shown. Although the wet seasons tend toward increased DSF over eastern equatorial Africa and the southwest Indian Ocean and reduced DSF over most of the rest of southern Africa, the dry seasons have important differences in the anomaly patterns with no 2 being identical. The only common feature in the dry seasons is the increased consistency of rainfall off the south coast, suggesting a northward shifted westerly storm track as suggested by Lindesay (1988). This reduced DSF south of Africa is particularly noticeable during the 1982/83 and 1991/92 dry seasons. The most reduced DSF values (i.e. most consistent rainfall) occurred during the 1980/81, 1988/89, 1995/96 and 1999/00 seasons, the last 3 being La Niña events.

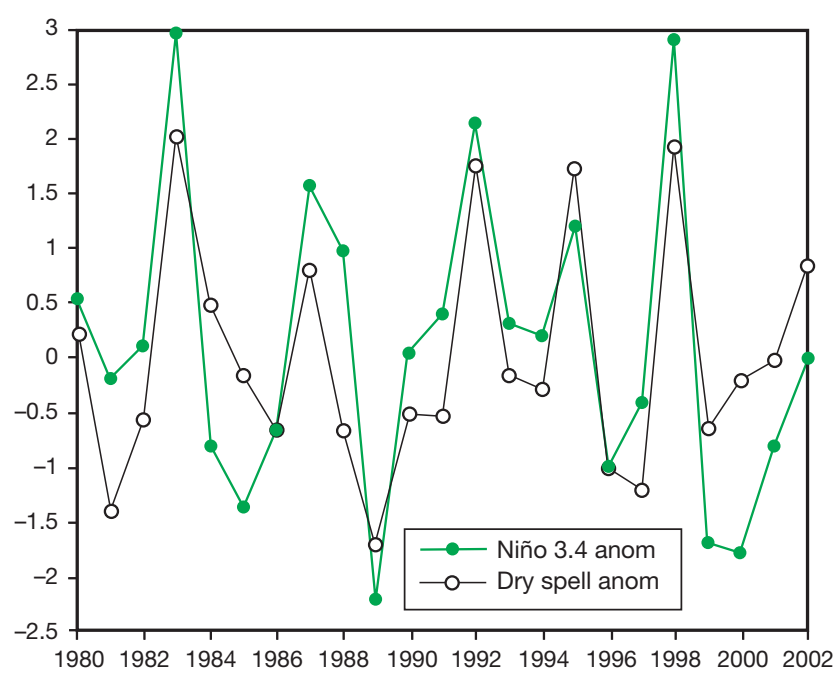

Fig. 4. Time series of normalised anomalies in dry spell frequency and Niño 3.4 sea surface temperature for the 1979/80 to $2001 / 02$ summer period
For southern Africa as a whole, the least departures in DSF from the mean generally occurred during the 1984/85 and 1985/86 seasons, while the most intense and widespread departures occurred during the 1982/83 and 1997/98 El Niño and 1999/00 La Niña seasons (Fig. 3). The extreme 1997/98 El Niño event is shown in the distinct reduction in DSF over East Africa and a marked increase over central southern Africa and western Angola. This contrasts with the reported 'good' rains during this season over these areas of southern Africa by several sources and suggests the significance of DSF as an indicator of ENSO impacts during the austral summer.

The potential for DSF to act as an indicator for ENSO impacts can be tested further by considering relationships with Niño 3.4 SST anomalies (Fig. 4). When DSF are computed from a spatial average of all of southern Africa except the equatorial and south coastal regions (5 to $30^{\circ} \mathrm{S}, 15$ to $40^{\circ} \mathrm{E}$ ), a close relationship between DSF and ENSO is apparent. This relationship is particularly strong for the El Niños of 1982/83, 1986/87, 1991/92 and 1997/98 and La Niñas of 1988/89, 1995/96, 1998/99 but weakens slightly during neutral seasons such as 1983/84 and 1985/86 when other forcing may be important and DSF is closer to average. Over the entire period, DSF and Niño 3.4 SST are correlated at 0.83 but this drops to 0.8 if only the 1980 s are considered and increases to 0.88 for 1990 to 1999. Similar plots (not shown) were constructed for various regions such as northern Namibia, northern Mozambique/

southern Tanzania, Zambia, Angola and central and northern South Africa. These all showed a coherent and marked relationship between DSF and Niño 3.4 SST anomalies but are strongest for central southern Africa (Zambia, Zimbabwe, Angola) and weakest for the northern Mozambique/southern Tanzania region, where western Indian Ocean SST anomalies that may evolve independently of ENSO (Behera \& Yamagata 2001, Reason 2001, 2002) can be important.

\subsection{Prolonged dry spell occurrences}

The susceptibility of particular areas of southern Africa to summer drought can be seen from Fig. 5. This figure plots the number of seasons out of the total of 23 during 1979/80 to 2001/02 that experience 6 or more dry pentads, shown as contours, and those with 9 or more dry pentads, shaded in colour. Since a given summer is 18 pentads long, this indicates whether that particular season was dry at least one-third and onehalf of the time respectively. Thus, one-third of the summer was dry during many of the last $23 \mathrm{yr}$ in a broad belt across southern Africa between 20 and $34^{\circ} \mathrm{S}$ interrupted only by 2 centres of relatively increased 


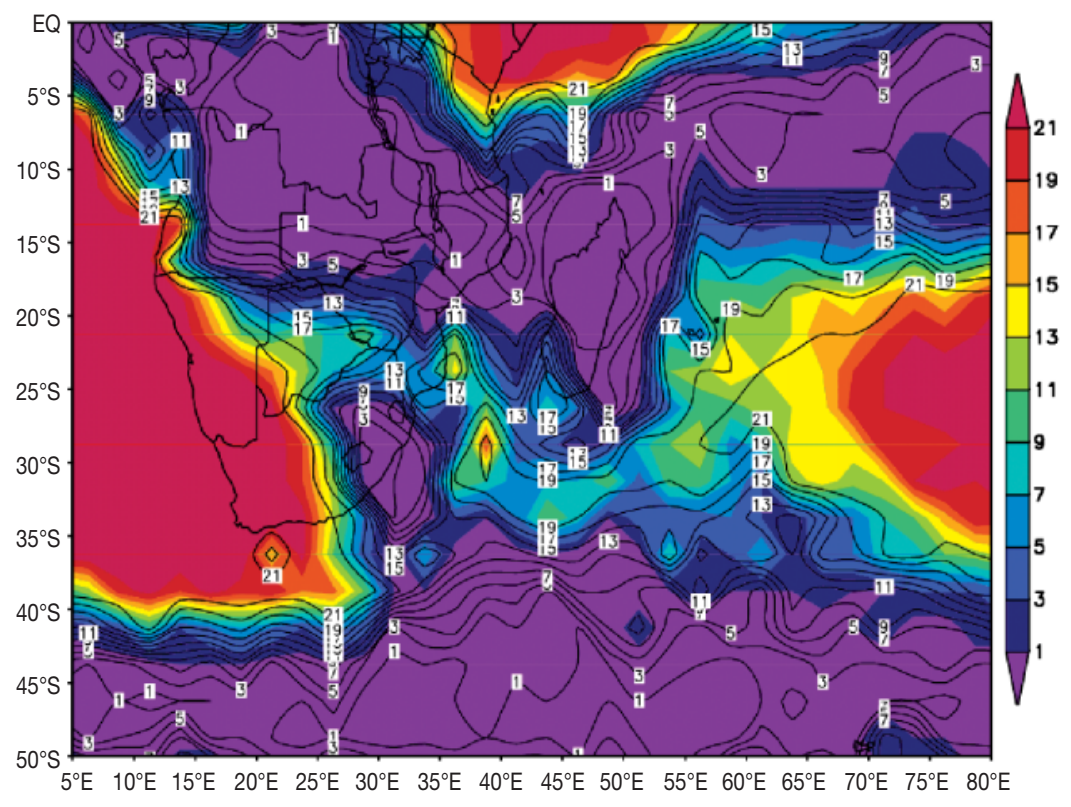

Fig. 5. Intensity-frequency map indicating susceptibility to dry spell occurrences. The number of seasons during 1979/80 to 2001/02 with 6 or more dry spells is shown in contours at an interval of 2, and with 9 or more shaded in colour at intervals of 2

convection. These are eastern Madagascar, and the area over, and downstream of, the Drakensberg and neighbouring mountain ranges in Lesotho, eastern South Africa and Swaziland. This implies that the occurrence of dry spells (at least up to 6) is a typical seasonal feature over a large part of the region. It is observed however that most of the dry spells actually occurred in December and were less common during the months of January and February (not shown). This may result since December is a transitional month when tropical weather systems start to become more dominant. Within the 20 to $34^{\circ} \mathrm{S}$ zonal belt described above, a 'drought corridor' region may be defined across 20 to $25^{\circ} \mathrm{S}$ (northern South Africa, southern Zimbabwe and Mozambique, Botswana and Namibia) which frequently experiences half or more of the season under dry spells. It is significant that, with the exception of the high frequencies over the permanently dry regions to the southwest during summer, all the seasons that produced this pattern coincided with El Niño events (cf. Fig. 2).

Fig. 6 shows the range of interannual variability in DSF determined as the difference between the maximum and minimum number of summer dry spell occurrences for each grid point during the
$1979 / 80$ to $2001 / 02$ period. Over the land, the main areas of high interannual variability in DSF during summer (and hence largest uncertainty in rainfall characteristics for a given summer) are northwestern Angola, southern Madagascar and northern South Africa/southern Zimbabwe and southern Mozambique. Interannual variability in DSF in the great lakes/ northern Tanzania region is not significant, since December to February is climatologically a dry season. Over parts of the drought corridor region, as well as over a significant fraction of the maize growing areas of South Africa, Zimbabwe and Mozambique, this range in DSF is 6 to 8 pentads in magnitude, which represents a potential difference in crop growing days between any 2 successive summers of up to 30-40 d. Such a large range imposes considerable uncertainty on farming and water resource management. Fig. 6 also shows that least interannual variability in DSF occurs near the ITCZ regions of northern Mozambique and Madagascar, the Congo basin, and the dry southwestern parts of the region. Relatively little interannual variability occurs over the Drakensberg Node 1 and eastern Madagascar Node 3 regions of the preferred locations of the TTTs.

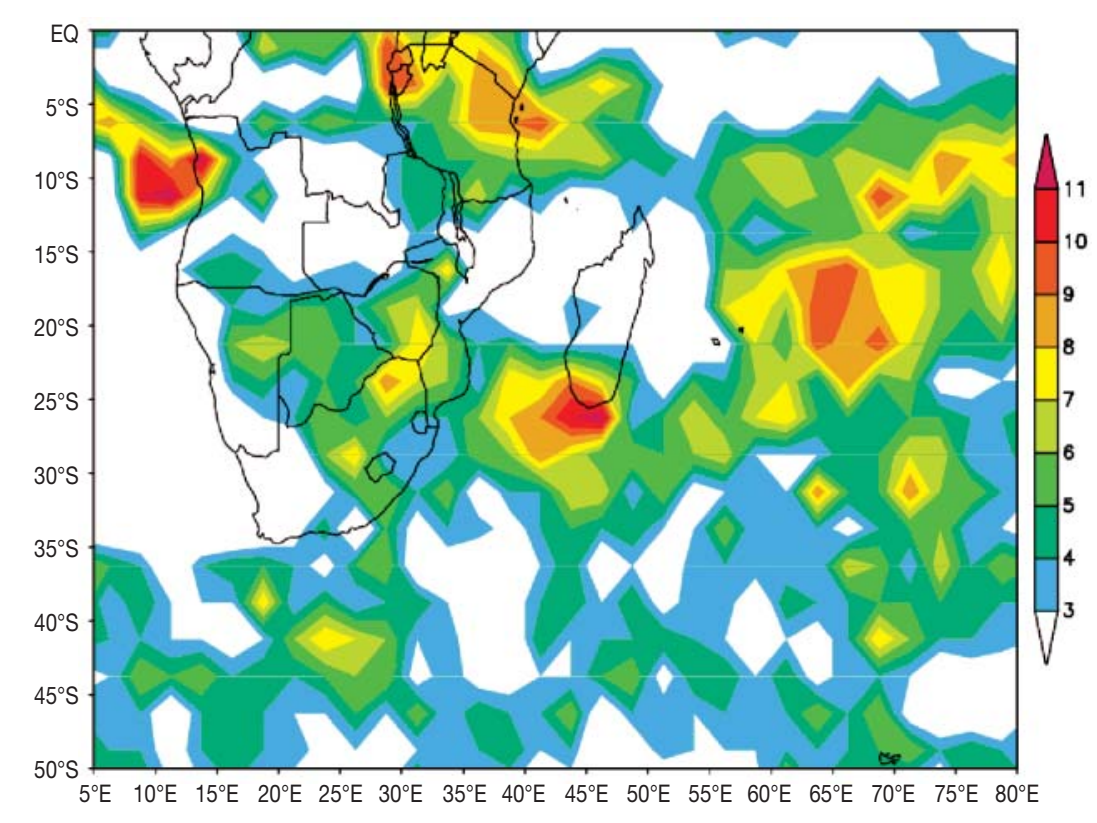

Fig. 6. Range of variability in dry spell frequency regime during 1979/80 to 2001/2 summers 

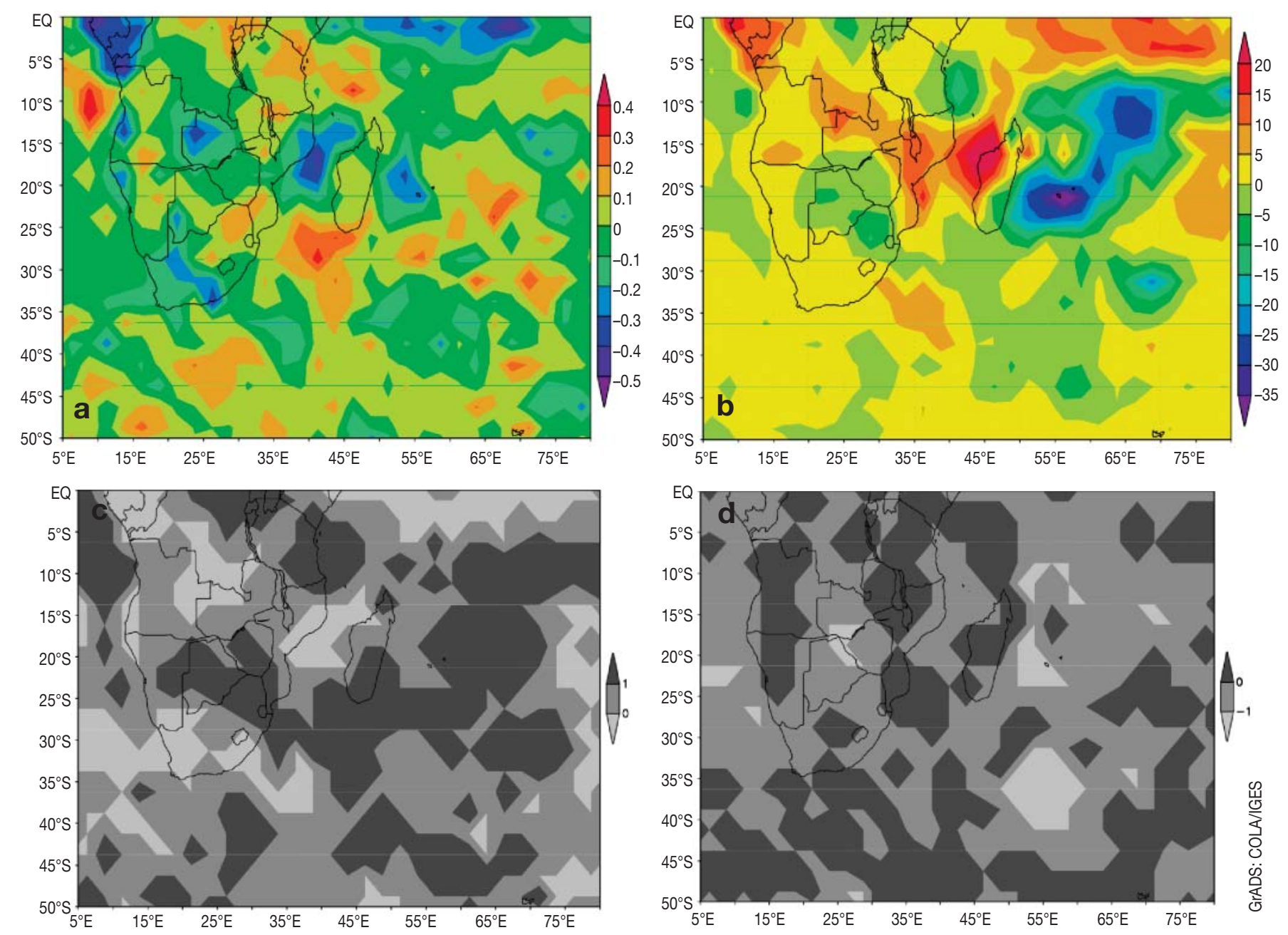

Fig. 7. (a) Change in summer dry spell frequency during 1979/80 to 2001/02. (b) Rate of change in summer rainfall (mm decade ${ }^{-1}$ ) during 1979/80 to 2001/02. (c) Areas that appear to be getting drier are flagged as above 1 (dark shades) and wetter as below 0 (light shades). Only areas that are statistically significant at $95 \%$ are so flagged. Medium grey shading refers to areas with insignificant changes. (d) Areas that appear to be receiving more intense rainfall events are flagged as above 0 (dark shades) and less intense as below -1 (light shades). Only areas that are statistically significant at $95 \%$ are so flagged. Medium grey shading refers to areas with insignificant changes

\subsection{Changes in dry spell characteristics during $1979 / 80$ to $2001 / 02$}

To examine whether there are any apparent changes in rainfall characteristics during 1979/80 to 2001/2, Fig. $7 \mathrm{a}, \mathrm{b}$ respectively plot the overall linear rate of change in DSF and in the seasonal rainfall total. It should be noted that this period is too short to indicate any secular trend and that much of southern Africa experiences significant decadal-interdecadal variability in rainfall (e.g. Tyson et al. 1975, Reason \& Rouault 2002, Allan et al. 2003). Nevertheless, it appears that the highest linear rates of change in DSF occur over the areas with the largest interannual variability (Fig. 6). Fig. 7b suggests noticeable changes in summer rainfall totals. In addition, areas of largest increase in rainfall during the period tend to correspond with those experiencing the most decrease in DSF (Fig. 7a). However, there is less agreement between areas of least change in both DSF and seasonal total, suggesting that important underlying differences exist.

To explore these differences, Fig. 7c shows in dark shading those areas over which the DSF increased during $1979 / 80$ to $2001 / 02$ but seasonal rainfall totals decreased, thus tending towards drier conditions. Areas where the reverse occurred (light shading) reflect wetter conditions. Generally, the confluence area between the Angola low and the ITCZ over southern Congo and northern Zambia tended to get wetter during the period whereas those along the drought corridor (and extending southeast over the east coast of South Africa) showed a drying tendency. In contrast, 
the naturally dry parts of the southwestern coast and the winter rainfall regions of the south coast appear to show slightly wetter summers.

Areas over which rainfall was less consistent during $1979 / 80$ to 2001/02 but seasonal totals increased represent areas where there has been an increase in heavy rainfall events, and these are shown in dark shades in Fig. 7d. Light shaded areas in Fig. $7 d$ are the reverse, i.e. regions where the rainfall was more consistent but seasonal totals reduced, implying an increase in light rainfall events. Note that in both Fig. $7 \mathrm{c} \& \mathrm{~d}_{\text {, }}$ only areas that are significant at the 95\% level are shaded as dark or light, grey shading refers to insignificant changes. The most significant increases in occurrences of heavy rainfall events (dark shading) are observed in central Namibia and Angola in the west, and over large areas in Tanzania, Zambia, Malawi and northwestern Mozambique in the east. Only a small region in northern Botswana/southern Zambia appears to show the reverse, i.e. more events with light rainfall.

\section{SUMMARY AND DISCUSSION}

Analyses of DSF have enabled the assessment of consistency of rainfall events and their interannual variability. Fig. 1 shows that the highly consistent rainfall regions are coincident with the ITCZ and the westerlies south of Africa. The dry western and southwestern coasts are also clearly distinct. This implies a direct association between rainfall receipt and DSF over these areas. In this regard, Fig. 2 shows that the recent droughts over southern Africa during the austral summer (December to February inclusive) have been associated with high DSF (low consistency in rainfall) and the good rainfall seasons with low DSF (high consistency in rainfall). On average, 7 or more dry spells during summer occur only over areas that are not naturally suitable for rain-fed cropping and are only used to support livestock.

The DSF parameter is useful in providing another measure of a season's rainfall characteristics besides the total and its deviation from the mean. 1997/98 is a good example where some sources reported good rains over large parts of the region but DSF was above average, indicating more erratic rainfall. This situation essentially resulted from above-average rainfall in March received during a few widely spaced heavy rainfall events. Weak normalised difference vegetation index response patterns reported by Anyamba et al. (2002) may be a direct consequence of this because vegetation response to change in rainfall is not immediate. The 1997/98 seasonal rainfall appears to show mixed signals in many respects, and identifying reasons for its departure from expected ENSO impacts is an important challenge. As Cook (2000) suggested, efforts should be directed at understanding the different pathways through which the ENSO signal propagates into southern Africa, since this could be the moderating factor. In the meantime, this season made headlines because of the failed forecast of El Niño-driven negative rainfall departures but the question remains whether crops would have done well within a high DSF regime. Also important is the question of how useful current forecast methodologies are to the various user groups in the region.

During the 1998/99 season, the area of increased consistency in rainfall was located more over the Mozambique Channel and neighbouring land, suggesting an eastward shift in the general pattern of reduced DSF on land during wet seasons and over the southwest Indian Ocean during dry seasons - probably a direct influence of the tropical cyclones (Alda and 21S) that approached the southern coast of Mozambique. Other tropical cyclone influences on seasonal rainfall include Eline in 1999/00 and Domoina in 1983/84.

The reduced consistency of the mid-latitude troughs feeding into the TTTs during the 1988/89 season shown in Fig. 2 is also evident in Fig. 3, with the dominant rain-bearing system apparently a southward extending tropical low as was the case to a less significant degree during the 1999/00 season. Since the TTTs are tropical-extratropical cloudbands that link a tropical low over low-latitude southern Africa with a westerly disturbance passing south of the landmass, they can be amplified if the tropical low is deeper or further south than average. During the 1993/94 and 1995/96 seasons, the band of increased consistency of rainfall split into two, with nodes in South Africa, Namibia and Botswana, suggesting cut-off lows rather than TTTs as the dominant rain-bearing systems.

Generally, it is known that TTTs are the dominant rain-producing systems over southern Africa, with their variability directly affecting that in southern African rainfall (e.g. Washington \& Todd 1999). Whether or not the TTT is truncated to just the landmass rather than extending south out over the southwest Indian Ocean has important implications for regional rainfall. The most favourable rainfall conditions over most of the region are provided by a TTT extending from south of South Africa deep inland to the main tropical low over the west of the subcontinent (Node 1). On satellite images, this shows up as a continuous band of clouds aligned roughly NW-SE across southern Africa. This type was dominant during the 1980/81 and 1999/00 seasons. However, sometimes this band is truncated so that it extends only as far south as Lesotho/eastern South Africa, which may lead to very wet conditions in the southeast as dominantly occurred during 1984/85 since the moisture and heat 
being transported polewards from the tropical low is mainly confined to the southeast of the landmass. If the tropical source of the cloudbands mainly lies over Madagascar (Node 3), then a poor rainfall season typically occurs across much of southern Africa, particularly along the drought corridor of Botswana, northern South Africa, southern Zimbabwe and Mozambique (e.g. 1991/92). Finally, if the tropical source tends to be mainly located in the Mozambique Channel (Node 2), then good rains over the eastern half of southern Africa and poor rains over the western half typically result (e.g. 1985/86).

The occurrence of dry spells is a normal seasonal phenomenon as indicated by the high frequencies of cumulative occurrences of 6 or more dry pentads. The fact that occurrences of a season which is dry more than half the time (i.e. 9 or more pentads out of a total of 18 during the 3 mo season) along the drought corridor tallied with the occurrence of El Niño is an indication that the impacts of these events also manifests (perhaps better) in reduced consistency of rainfall and not just in departures from mean rainfall. In general, DSF was increased (decreased) over large areas of southern Africa during El Niño (La Niña) events. These results support the earlier assertion that DSF should be integrated into seasonal forecasting efforts for improved usefulness.

It should be noted that, due to availability of data, this study has used pentad ( $5 \mathrm{~d}$ mean) rather than daily data. As a result, it is possible for a dry or wet spell to occur across 2 pentads without being reflected in either one of these 2 pentads themselves. The implication of using pentad data is that the results presented here really represent lower bounds on the frequency of dry spells and their variability since increased values could occur if dry spells were defined using daily data, were the latter available.

An important feature of the spatial extent of dry spell occurrences is the location of isolated cells of maximum frequency just off the coast of southern Mozambique (Fig. 5). The cells appear to vary in both size and location (Fig. 2) and appear to be directly associated with enhanced dry conditions over southern Mozambique and Zimbabwe. They may be linked to SST anomalies in the southwest Indian Ocean, which have been shown by many researchers to influence the regional atmospheric circulation and rainfall (e.g. Walker \& Shillington 1990, Reason \& Mulenga 1999, Behera \& Yamagata 2001, Reason 2001), or they may result from adjustments to the regional Walker circulation (Shinoda \& Kawamura 1986, Jury 1992, Jury et al. 1994, Stokes et al. 1997). An example of their significance is the 1988/89 La Niña season (Fig. 2). Even though Node 1 links were dominantly frequent during this season as expected, rainfall was significantly less consistent over the eastern half of the drought corridor from eastern Botswana through to southern Mozambique than in the western half.

The drought corridor also experiences a greater range of occurrence of dry spells during 1979/80 to 2001/02. A range higher than 3 pentads is considered significant in that if the spells occur in a stretch during the middle of the season, the impact on water availability and crops is bound to be great. It is therefore significant that over parts of the maize growing areas of South Africa, Zimbabwe and Mozambique, this range is 6 to 8 pentads in magnitude. This represents a potential difference in crop growing days between any 2 successive summers of up to $30-40 \mathrm{~d}$, imposing an underlying degree of uncertainty on farming operations and crop yield potentials as well as posing problems for water resource management. Since this range is usually independent of total seasonal rainfall, forecast information indicating above- or below-normal rainfall may not be of much help to the farmer or to water managers. Growing season distribution of the rains (or dry spell frequency and duration) therefore requires greater attention in forecast attempts. The apparent linkage between DSFs and ENSO holds out hope that they may be predicted with reasonable lead and accuracy.

Although DSFs were generally above normal during El Niño seasons and below normal during La Niña seasons, intriguing questions remain unanswered. These include studying why the intense El Niño event of 1997/98 produced the right magnitude of negative DSF anomalies over East Africa but a weaker magnitude of positive anomalies over southern Africa and why the centres of most consistent rainfall are located in different parts of southern Africa during the various La Niña seasons.

Acknowledgements. The authors gratefully acknowledge the University of Cape Town for funding this research effort. We thank B. Hewitson, D. Jagadheesha and C. Jack for helpful discussions. S. Hachigonta assisted with some of the graphics. M.T.U. thanks T. Mitchell for initial guidance and direction.

\section{LITERATURE CITED}

Allan RJ, Reason CJC, Lindesay JA, Ansell TJ (2003) Protracted ENSO episodes and their impacts in the Indian Ocean region. Deep-Sea Res 50:2331-2347

Anyamba A, Tucker CJ, Mahoney R (2002) From El Niño to La Niña: vegetation response patterns over east and southern Africa during the 1997-2000 period. J Climate 15:3096-3103

Behera SK, Yamagata T (2001) Subtropical SST dipole events in the southern Indian Ocean. Geophys Res Lett 28: $327-330$

Cook KH (2000) The South Indian convergence zone and interannual rainfall variability over southern Africa. J Climate 13:3789-3804 
Harangozo S, Harrison MSJ (1983) On the use of synoptic data in indicating the presence of cloud bands over southern Africa. S Afr J Sci 79:413-414

Harrison MSJ (1984a) A generalized classification of South African summer rain-bearing synoptic systems. J Climatol 4:547-560

Harrison MSJ (1984b) Comparison of rainfall time series over South Africa generated from real data and through principal component analysis. J Climatol 4:561-564

Jury MR (1992) A climatic dipole governing the interannual variability of convection over the south west Indian Ocean and southeast Africa region. Trends Geophys Res 1: 165-172

Jury MR (1999) Intra-seasonal variability over southern Africa: principal component analysis of pentad outgoinglongwave radiation departures 1976-1994. Theor Appl Climatol 62:133-146

Jury MR, McQueen CA, Levey KM (1994) SOI and QBO signals in the African region. Theor Appl Climatol 50: 103-115

Levey KE, Jury MR (1996) Composite intra-seasonal oscillations of convection over southern Africa. J Climatol 9: 1910-1920

Lindesay JA (1988) South African rainfall, the Southern Oscillation and a Southern Hemisphere semi-annual cycle. J Climatol 8:17-30

Lindesay JA, Jury MR (1991) Atmospheric circulation controls and characteristics of a flood event in central South Africa. Int J Climatol 11:609-697

Lyons SW (1991) Origins of convective variability over equatorial southern Africa during summer. J Climate 4:23-39

Mason SJ (1995) Sea surface temperatures-South African rainfall associations, 1910-1989. Int J Climatol 15:119-135

Nicholson SE, Entekhabi D (1987) Rainfall variability in equatorial and southern Africa: relationships with sea surface temperatures along southwestern coast of Africa. J Clim Appl Meteorol 26:561-578

Nicholson SE, Selato JC (2000) The influence of La Niña on African rainfall. Int J Climatol 20:1761-1776

Reason CJC (2001) Subtropical Indian Ocean SST dipole events and southern African rainfall. Geophys Res Lett 28:2225-2227

Reason CJC (2002) Sensitivity of the southern African circulation to dipole SST patterns in the South Indian Ocean. Int J Climatol 22:377-393

Reason CJC, Mulenga H (1999) Relationships between South African rainfall and SST anomalies in the south west Indian Ocean. Int J Climatol 19:1651-1673

Reason CJC, Rouault M (2002) ENSO-like decadal patterns and South African rainfall. Geophys Res Lett 29(13): 10.1029/2002GL014663

Editorial responsibility: Andrew Comrie,

Tuscon, Arizona, USA
Reason CJC, Allan RJ, Lindesay JA, Ansell TJ (2000) ENSO and climatic signals across the Indian Ocean basin in the global context: Part 1, Interannual composite patterns. Int J Climatol 20:1285-1327

Schulze RE (1997) South African atlas of agrohydrology and climatology. Report TT82/96. 43, Water Research Commission, Pretoria

Shinoda M, Kawamura R (1986) Relationships between rainfall over semi-arid southern Africa and geopotential heights and sea surface temperatures. J Meteorol Soc Jpn 74:21-36

Sivakumar MVK (1992) Empirical analysis of dry spells for agricultural applications in West Africa. J Climate 5: $532-539$

Stokes S, Thomas DSG, Washington R (1997) Multiple episodes of aridity in southern Africa since the last interglacial. Nature 38:154-158

Taljaard JJ (1986) Change of rainfall distribution and circulation patterns over South Africa in summer. J Climatol 6:579-592

Tennant WJ, Hewitson BC (2002) Intra-seasonal rainfall characteristics and their importance to the seasonal prediction problem. Int J Climatol 22: 1033-1048

Todd MC, Washington R (1998) Extreme daily rainfall in southern African and southwest Indian Ocean tropicaltemperate links. South Afr J Sci 94:64-70

Todd MC, Washington R (1999) Circulation anomalies associated with tropical-temperate troughs over southern Africa and the southwest Indian Ocean. Clim Dynam 15:937-951

Todd MC, Washington R, Palmer P (2004) Water vapour transport associated with tropical-temperate trough systems over southern Africa and the southwest Indian Ocean. Int J Climatol 24:555-568

Tyson PD (1986) Climatic change and variability in southern Africa. Oxford University Press, Cape Town

Tyson PD, Dyer TGJ, Mametse MN (1975) Secular changes in South African rainfall: 1880 to 1972. Q J R Meteorol Soc 101:817-833

Usman MT (1994) On the instability of the troposphere during the onset phase of the West African summer monsoon. MTech thesis, Federal University of Technology, Minna

Walker ND, Shillington FA (1990) The effect of oceanographic variability on South African weather and climate. South Afr J Sci 86:382-386

Washington R, Todd M (1999) Tropical-temperate links in southern African and southwest Indian Ocean satellitederived daily rainfall. Int J Climatol 19:1601-1616

Xie P, Arkin PA (1997) Global precipitation: a 17 year monthly analysis based on gauge observations, satellite estimates and numerical model outputs. Bull Am Meteorol Soc 78: $2539-2558$

Submitted: January 13, 2003; Accepted: May 8, 2004

Proofs received from author(s): June 15, 2004 